\title{
Historical Aspects of Development of the Theory of Azimuthal Map Projections
}

\section{Rostislav Sossa, Pavel Korol}

The problem of adequate imaging of the Earth's surface on the plane of a map is not new. Over the past 2000 years mathematicians and cartographers throughout the world have been considering various methods of finding the ideal cartographic projection, but a priori the existence of such a projection is not possible, since the spheroid surface is not deployed on the plane without folds or breaks.

The historical aspects of the development of mathematical cartography and the theory of the fundamental scientific work that is dedicated to the history of map projections is the definitive book by John Parr Snyder ${ }^{6}$. Historical aspects of the theory of azimuthal map projections were not considered separately.

Azimuthal are map projections, parallels of which are represented by concentric circles, and the meridians - straight lines that intersect at the center of the circle (pole of projection) at an angle which equal to the difference of longitudes of corresponding meridians. From this

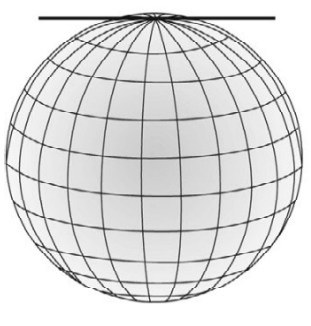

normal

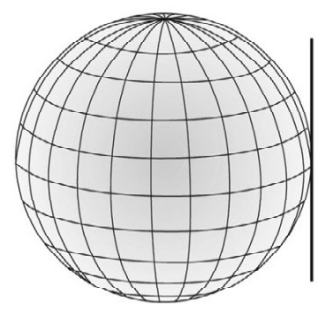

transverse

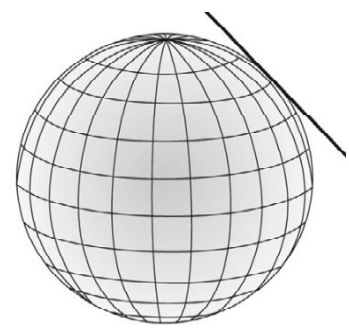

oblique

Fig. 1. Aspects of azimuthal projections.

Source: M. Kennedy, S. Kopp, "Understanding Map Projections", Redlands 1994-2000

map projections, as the main constituent have been considered in scientific papers by F.V. Botley ${ }^{1}$, J. Brian Harley, David Woodward ${ }^{2}$, Arthur H. Robinson, Joel L. Morrison, A. Jon Kimerling, Phillip C. Muehrcke, Stephen C. Guptill ${ }^{3}$, Eberhard Schröder ${ }^{4}$ and Waldo R. Tobler ${ }^{5}$. However,

1 F.V. Botley, British and American World Map Projections from 1850 1950, Univ. of London, Master's Thesis in Geography, 1952.

2 J.B. Harley, D. Woodward, The History of Cartography, vol. 1-2, Chicago 1987-1994.

3 A.H. Robinson, J.L. Morrison, Ph.C. Muehrcke, A.J. Kimerling, S.C. Guptill, Elements of Cartography, New York 1995.

4 E. Schröder, Kartenentwürfe der Erde. Kartographische Abbildungsverfahren aus mathematischer und historischer Sicht, Frankfurt am Main 1988.

5 W.R. Tobler, Medieval Distortions. The Projections of Ancient Maps, „Annals of the Association of American Geographers”, 56 (2), 1966 , pp. 351-361. definition it follows that the azimuthal projections is a particular type of conic projection. The point of convergence of meridians in the azimuthal projections coincides with the position of the pole of a normal coordinate system. Depending on the type of functions, properties of the azimuthal projections (conformality, equivalence, equidistance) are defined.

Depending on the position of the tangent point on the Earth's surface, azimuthal projections are divided into three aspects: normal (polar), if the tangent point is on the pole, transverse (equatorial), if the tangent point

\footnotetext{
6 J.P. Snyder, Flattening the Earth. Two Thousand Years of Map Projections,
} Chicago 1993. 
is on the equator, and oblique (horizontal), if the tangent point is in any other place on the Earth surface.

Depending on the placement of the picture plane relative to the Earth's surface, the azimuthal projection may be tangent or secant. For azimuthal projections, which use a tangent plane, the tangent point is a point of zero distortion, and for projections using a secant planes, a secant circle is a line of zero distortion. In both cases, lines of equal distortions have the form of concentric circles that coincide with and Southern hemispheres, usually a normal aspect is used, for maps of the Western and Eastern Hemisphere a transverse aspect is used, and for maps of continents and parts of continents - oblique azimuthal projection is used.

Some azimuthal projections that were known 2500 years ago have not lost their theoretical and practical importance in our times, although they are used primarily in small-scale mapping.

Depending on the nature of the constructing, azimuthal projections are divided into perspective and non-perspective. According-

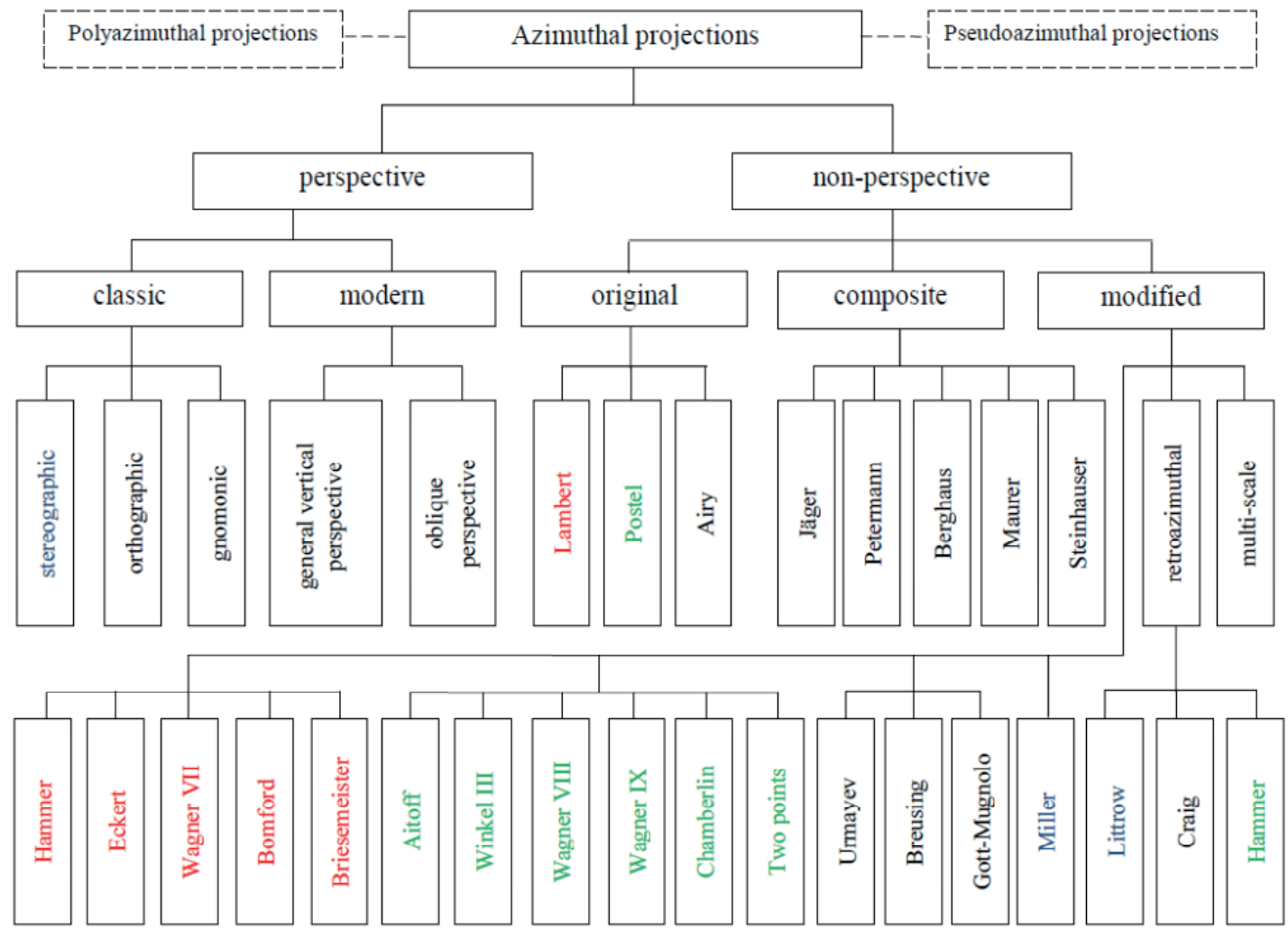

Fig. 2. General classification scheme of azimuthal map projections.

Note: in blue font marked conformal, in red - equal-area, in green - equidistant, in black - other arbitrary azimuthal projections

the parallels of a normal grid. Distortions of all types grow with distance from the point or line of zero distortion.

Azimuthal projections in normal, transverse and oblique aspects are widely used for the mapping of areas with a rounded shape. In particular, for the construction of maps of the Northern ly, we developed a general classification scheme of azimuthal map projections that are shown in figure 2 . Despite the limited variability of variables in the equations of azimuthal projections, the number of modifications, as opposed to cylindrical and conical projections, are virtually unlimited. 


\section{Perspective projections}

A perspective azimuthal projection is obtained by projecting points of the Earth's surface onto a picture plane by rays propagating from a certain constant perspective point. A picture plane may be secant, tangent to the Earth or it may be at a certain distance from it, and a perspective point located on the perpendicular to the picture plane passing through the center of the Earth.

Depending on the position of the prospect's point relative to the center of mass of the Earth, perspective azimuthal projections are divided into: orthographic, if the prospects point is removed to infinity; external, if the prospects point is located at some distance from the center of mass of the Earth; stereographic, if the distance from the center of mass of the Earth

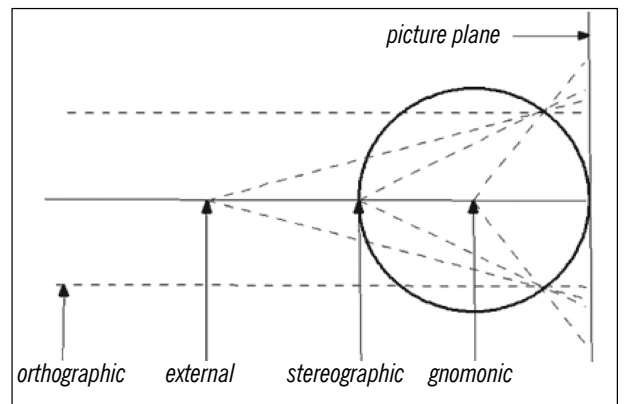

Fig. 3. Types of perspective azimuthal projections.

Source: Л.М. Бугаевский „,Математическая картография", Москва 1998

to a prospects point is equal to the radius of the Earth, i.e. prospect's center is located at the point opposite the point of contact to picture plane; and gnomonic (central), if the prospect's point is placed in the center of the Earth.

Gnomonic, stereographic and orthographic projections form a group of classic perspective azimuthal projections, and externals a group of modern perspective azimuthal projections.

\section{Classic perspective projections}

Gnomonic (central, azimuthal centrographic or gnomic) projection is based on the principle of azimuthal stereographic, but a perspective point is situated in the center of the sphere, therefore it is used for the mapping of territories which have less than one hemisphere. Projection refers to the class of arbitrary perspective azimuthal projections. The gnomonic projection is said to be the oldest map projection. It was developed by ancient Greek philosopher Thales of Miletus (624-546) about 580 BC. The name of this projection comes from the gnomon sundial, whose hourly shadows reflect on the image plane one meridian of mapping grid. The peculiarity of this projection is that all great circles (meridians and the equator) are straight lines on it in such a way that the shortest distance between two points on the map is a straight line. In the past, a projection was used for creating celestial maps and multifaceted globes. It is currently used in navigation for plotting direction finding bearings, and in astronomy for observing meteors (Lorenzoni nets), in seismology for mapping propagation directions of seismic waves, in multidimensional hyperbolic, in geometry for constructing of Beltrami-Klein projective model, and in photography for receiving the images from camera obscura or rectilinear lenses.

Stereographic (Ptolemy planisphere) projection refers to the class of conformal perspective azimuthal projections, the perspective point of which is located in a nadir point. Stereographic projection (from the Greek: $\sigma \tau \dot{\varepsilon} p \varepsilon \circ-$ solid, ypaфixós - drawing) was proposed in the second century BC by an ancient Greek astronomer Hipparchus (190-126), but for a long time the scope of its use was limited by maps of the star sky. It is believed that one of the earliest maps of the world, established in stereographic projection, is a map of the French mathematician Gualterious Lud (1507). The transverse aspect of stereographic projection was used by Jean Rose (1542) and Rumold Mercator (1595). The current name of the projection was proposed by the French mathematician François d'Aguilon (1613) in work Opticorum libri sex philosophis juxta ac mathematicis utiles. All great and small circles (including meridians and parallels) on the Earth's surface, represented as arcs of concentric circles or straight lines, and the rhumb lines have a form of logarithmic spiral. In the mathematical sense, ste- 


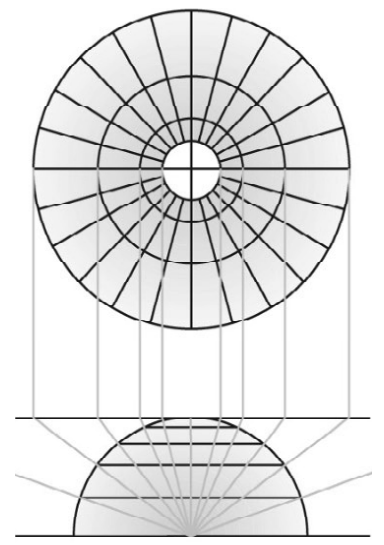

gnomonic

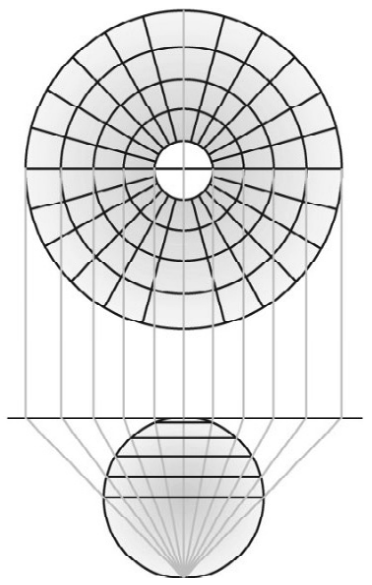

stereographic

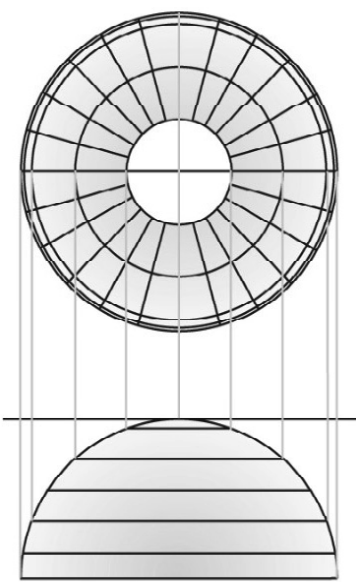

orthographic

Fig. 4. Types of classic perspective azimuthal projections. Source: M. Kennedy, S. Kopp, "Understanding Map Projections"
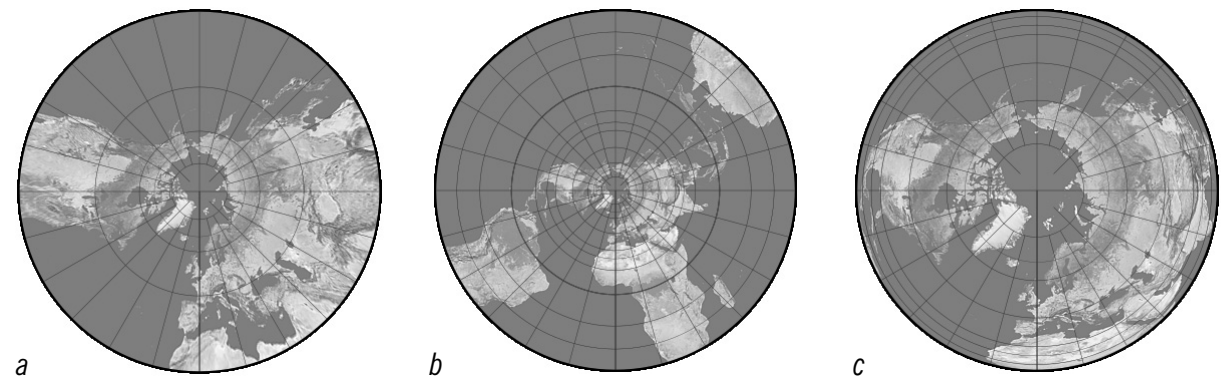

Fig. 5. Classic perspective azimuthal projections: a) gnomonic; b) stereographic; c) orthographic. Source: D. Strebe, “Geocart 3. User's Manual. Manual describes Geocart 3.1", Seattle 2009

reographic projection is conformal mapping it preserves angles between curves and the shape of infinitesimal pieces, transforming circles on the plane in the circle on the sphere, and on the plane - in a circle passing through the center of projection. It provides a homeomorphism of complex projective line in the transition to a two-dimensional sphere, and moves its sphere generating a Moebius transformation on the complex plane. In general, the projection is used for conformal mapping of round areas. The normal aspect of the stereographic projection is widely used to create topographic maps of the polar regions; the transverse was used to create maps of the Eastern and Western hemispheres in $17^{\text {th }}-18^{\text {th }}$ centuries, and oblique was used to display the paths of solar eclipses. Stereographic projection is used for a visual display of point symmetry groups of crystals, as well as for displaying spherical panoramas.

Orthographic (orthogonal or Ptolemy analemma - sundial latitude and longitude) projection refers to the class of arbitrary perspective azimuthal projections which has been used in the design of a system of parallel rays emanating from a center that are removed to infinity. Geometric justification of orthographic projection is the simplest compared to other azimuthal projections. Orthographic projection (from the Greek: op $\theta_{0}$ - straight, $\gamma p a \phi ı o^{\prime} s$ - drawing) was proposed in the second century BC by the ancient Greek mathematician

\section{I9O Studia Geohistorica ・ Nr 03. 2015}


Apollonius (262-190) and used for mapping of areas that are limited by one hemisphere. About 14 BC, the Roman engineer Marcus Vitruvius Pollio used the orthographic projection in the construction of a solar clock and for computing its location. In 1613, François d'Aguilon from Antwerp offered its present name for the projection. The earliest references to the use of projection are engraved terrestrial globe on wood by an unknown author (1509) and works of Johannes Schöner $(1533,1551)$ and Apian (1524, 1551). The original map in orthographic projection was designed by the distinguished engraver of the Renaissance Albrecht Dürer and executed by Johannes Stabius (1515). Orthographic perspective projection of the world on the tangent plane of the perspective point that is removed to infinity provides a globular form of the image as used to create artistic images of the Earth, especially terrestrial landscapes from space. Using the orthographic projection in atlases was limited mainly to maps, but at the present stage of space exploration, much attention is paid to high quality images of the moon and other planets from the orbit, which has caused considerable revival of interest in this projection.

\section{Modern perspective projections}

When taking a picture of the Earth from the Space, the camera fixes images in an external perspective projection. If the camera is precisely directed to the center of the Earth, then the observers get a General Vertical Perspective projection, and otherwise - Tilted Perspective projection. These projections are a group of modern perspective azimuthal projections.

General Vertical Perspective projection refers to the class of arbitrary perspective azimuthal projections (except stereographic version); however, unlike orthographic, a projective point is not at infinity, but is situated at some fixed distance from the Earth's surface, usually from a few hundred to tens of thousands kilometers. Some versions of this projection were known to the Greeks and the Egyptians 2000 years ago. The General Vertical Perspective projection can be defined by straight lines converging at an arbitrary zenithal point on a line passing through the center of the Earth and perpendicular to the projection plane, which is usually tangent at the Earth surface. Because it is a perspective projection, for each point on Earth the line passing through it defines the former's projection where it intersects the plane. The projection is parameterized by the distance between the convergence point and the center of the Earth; it is the general case of the azimuthal orthographic, stereographic and gnomonic projections. General Vertical Perspective projection is a limiting case of the Tilted Perspective projection, which does not require the projection plane to be perpendicular to the convergence line and is not necessarily azimuthal.

The General Vertical Perspective projection is found in two varieties: "near-sided", when the convergence point is "above" the mapped surface, and "far-sided", when "below" it. The first kind reproduces a view from the air or space directly downwards, bounded by a circular horizon, which is limited by the curvature of the globe; the visible angular range grows to a maximum of $90^{\circ}$ (a whole hemisphere) of the zenith at infinity, which is the classic orthographic projection. In contrast, the far-sided kind normally shows more than one hemisphere. The visible angular range shrinks with distance; the limiting case at infinity is again the orthographic. And, like the stereographic case, the projecting lines first "see" the inner face of the globe. Although near-sided general vertical perspective maps are limited to mimicking views from space, the far-sided variant was adopted by several authors who chose different projection distances in order to minimize global distortion according to arbitrary criteria. Such perspective projections were studied in $18^{\text {th }}-19^{\text {th }}$ centuries as minimum error projection, which has a geometric substantiation.

In order to minimize the overall distortion for arbitrary criteria, cartographers have used different distances from the nadir point to the perspective point. In particular, French astronomer Philippe de La Hire (1701) proposed to place a perspective point for a distance, which equals to 1.7071 of Earth's radius. Later, Antoine 
Parent (1702), Herman Heinrich Ernst von Hammer (1890) and Hans Theodor Julius Christian Karl Maurer (1935) proposed other variants of projection with low distortion. Sir Henry James and Alexander Russell Clark $(1857,1862,1879)$ proposed projections with coefficients, respectively, $1.5,1.368,1.4$, which are calculated at the points of the projection on

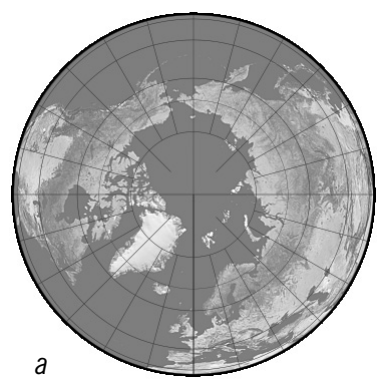

In 1981, American cartographer John Parr Snyder (1926-1997) proposed a modified arbitrary perspective azimuthal projection Tilted Perspective. The projection shows the Earth geometrically when removing an airplane or any other point in space. If the point is above the surface the projection used to create maps of individual areas (less than a hemisphere), the

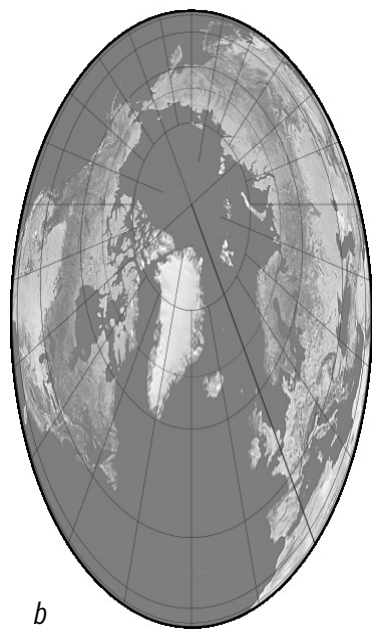

Fig. 6. Modern perspective azimuthal projections: a) general vertical perspective; b) tilted perspective. Source: D. Strebe, "Geocart 3. User's Manual"

the opposite side, below the projection surface and cover the continents, and are limited by great or small circles. To reflect the visible side of the Moon Albert Novicky (1963) offered to place a projective point on the distance of 1.53748 of the Earth's radius. In order to preserve the integrity of the continents' image, Sir James and Clark used secant planes and oblique variants of projection. In particular, Sir James proposed to use the angle of divergence of rays $-113^{\circ} 30^{\prime}\left(90^{\circ}+23^{\circ} 30^{\prime}\right.$, from the zenith to the visible horizon), and Clark, for its most famous variant "Twilight" proposed $108^{\circ}\left(90^{\circ}+18^{\circ}\right.$, the angle below the visible horizon which defines the astronomical twilight). The General Vertical Perspective projection is widely used in iconography and sacred art. Current projection used to create a new generation of Internet-mapping applications, including Google Earth and NASA World Wind allow interactive panning, zooming, and flight simulation. terrestrial landscapes resembles pictures from space, displaying the results of aerial removing and in photogrammetry.

\section{Non-perspective azimuthal projections. Original projections}

Equidistant azimuthal projection used by the ancient Egyptians to create maps of the star sky are shown in some sacred books, for example, in the works of a Muslim scholar and polymath of the $11^{\text {th }}$ century al-Biruni. Mathematical reasoning of the projection was made in 1581 by a French linguist, astronomer, theologian and cartographer Guillaume Postel (15101581). Postel projection is extremely simple in construction. The peculiarity of this projection is that the distance between two points along a straight line passing through the center of the projection is accurate, so it is often used in normal aspect, in order to minimize distortions often appearing for mapping hemispheres or polar re-

\section{I92 Studia Geohistorica • Nr 03. 2015}



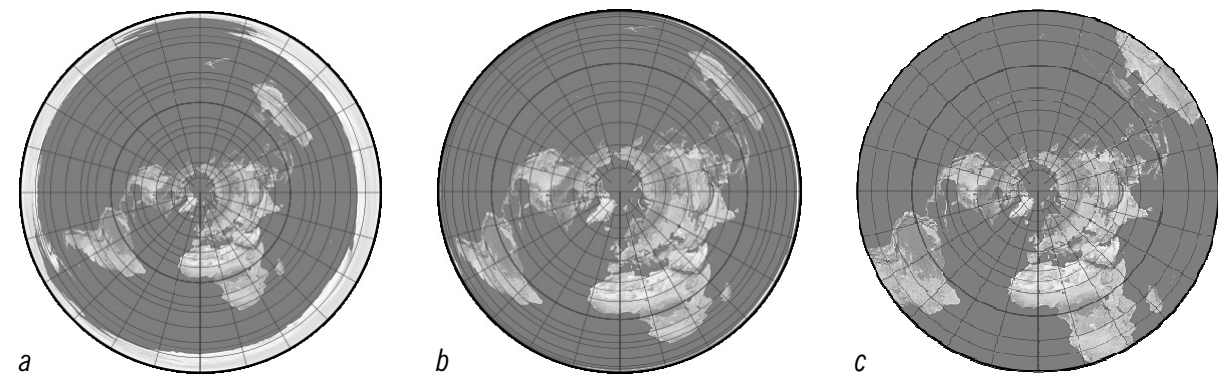

Fig. 7. Original azimuthal projections: a) Postel; b) Lambert; c) Airy. Source: D. Strebe, "Geocart 3. User's Manual"

gions. In north polar aspect equidistant azimuthal projection a fragment of the flag and emblem of the United Nations is used with a picture of olive branches in place of Antarctica. As an example, we can cite the use of equidistant azimuthal projection in the National Atlas of the United States (USGS), in large-scale mapping of Micronesia and Guam, in air navigation, in seismology, in radiodirection finding.

In 1772, the Swiss mathematician, physicist, philosopher and astronomer Johann Heinrich Lambert (1728-1777) developed equal-area azimuthal projection that resembles Postel equidistant azimuthal projection, but to preserve the scale of an area the distance between the parallels are reduced. Due to the simplicity of construction, the projection is used in all aspects, although normal aspect was proposed by Anton Mario Lorgna (1789), after the death of Lambert. Often normal aspect of projection is used for the mapping of the Northern and Southern hemispheres, the Arctic and Antarctic regions. Transverse aspect is used for maps of Western and Eastern hemispheres, and oblique aspect is used for maps of continents and oceans. Lambert equal-area azimuthal projection is used for visual analysis of maps, in pictures, and in the construction of spherical panoramas. As a result of combining equal-area azimuthal projection, Lambert and WilliamOlson projections formed a modified version of the Werner projection.

In 1861, a British mathematician, astronomer and geodesist Sir George Biddell Airy (1801-1892) proposed a non-perspective arbi- trary azimuthal projection - Airy Minimumerror Azimuthal, which is based on the condition of minimizing the distortion and is currently used to create medium-scale LandSurvey maps of the UK.

\section{Modified projections}

Some azimuthal projections are obtained by making certain changes in the equations of famous map projections. They are derived from the actual azimuthal projections and form a group of modified azimuthal projection, while others, such as star projections, which are formed by nucleus of azimuthal projection hemispheres, are folded or composite. The modified azimuthal projection is obtained by changing the metric space of one or more projections to obtain a cartographic image with desired properties. This group of azimuthal map projections is the most numerous.

Modified azimuthal projection of the German mathematician and cartographer Adam Maximilian Nell (1824-1901) called the Nell projection is an intermediate option between the ordinary globular projection and the stereographic projection of hemispheres. The geometric construction principle of the projection is as follows: meridians and parallels are curves that pass between the relevant meridians and parallels globular and stereographic projections. The projection is very rarely used for the creation of thematic maps in the atlases of the world.

In 1892, a German navigator Friedrich August Arthur Breusing (1818-1892) developed 
a geometric variant of the azimuthal projection - Breusing Geometric, and in 1920, Alfred Ernest Young created a harmonic variant as a modification of geometric variant - Breusing Harmonic. The visual projection is virtually identical to the Airy Minimum-error Azimuthal projection. Geometric and harmonic variants of Breusing projection generalize properties of stereographic projection and Lambert equalarea azimuthal projection, in particular distances between parallels of cartographic grid is calculated: in the first case - as the geometric
Orthodromic, Close, McCaw, Immler) respectively, and in 1919 and 1921, they also proposed an arbitrary modified azimuthal projection called the Two-point Equidistant (Doubly Equidistant), which is traditionally used in oblique aspect. The first one is used in sea direction finding, if the exact coordinates of two transmitters (two central points) and the direction of the ship on them are known. The other is used to determine the location of the ship at measured distances to it from the two central points, which set the station range for finding radio
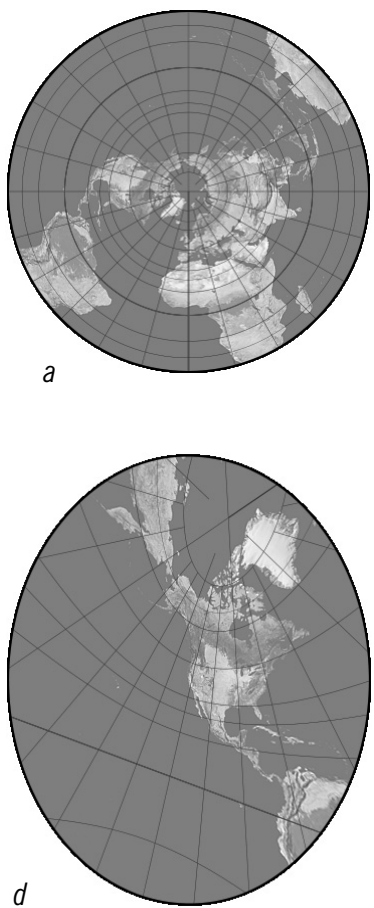
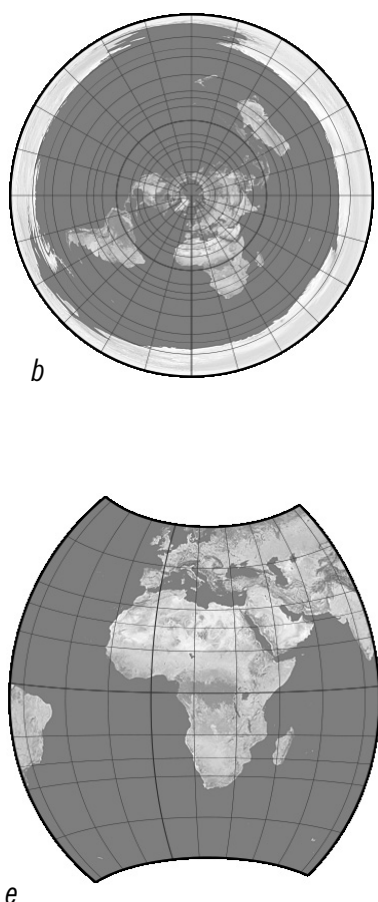
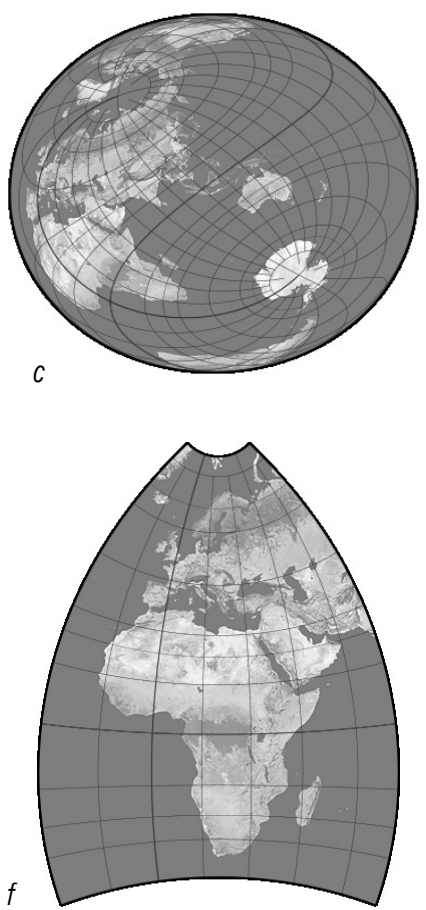

Fig. 8. Modified azimuthal projections: a) Breusing geometric; b) Breusing Harmonic; c) Two-point Equidistant; d) Two-point Azimuthal; e) Chamberlin trimetric; f) Miller Oblated Stereographic. Source: D. Strebe, “Geocart 3. User's Manual"

mean, and the second - as the harmonic mean of the distances between the parallels of the two aforementioned projections.

In 1914 and 1922, two outstanding cartographers of the $20^{\text {th }}$ century German Hans Theodor Julius Christian Karl Maurer (1868-1945) and British Sir Charles Frederick Arden-Close (1865-1962), independently proposed an arbitrary modified azimuthal projection Two-point Azimuthal (Doubly Azimuthal, navigation system. In addition, the projections are used to create maps of Asia, United States and Southern Canada, telegraph networks and sea routes of US National Geographic Society. A combined Two-point Azimuthal and Two-point Equidistant projection was proposed by Sir Charles Frederick Arden-Close in 1922.

In 1946, the American cartographer who led the U.S. National Geographic Society from 1964 to 1971, Wellman Chamberlin 
(1908-1976), developed a modified equidistant azimuthal balance of errors projection Chamberlin trimetric projection. It is used to create maps of individual parts of continents in National Geographic Atlas of the United States, including maps of Canada, Alaska and Greenland (1:8 000 000, 1947), Australia (1:6 000 000, 1948), Europe and Middle East (1:7 500000,1949$)$, Africa and Arabian peninsula $(1: 12000000,1950)$ and others.

In 1950, a Soviet cartographer Nikolay Andreevich Urmayev (1895-1959) developed two arbitrary azimuthal projections - Urmayev 1 and Urmayev 2. Although in the projections distortions of angles and areas are present, with properties they are very similar to minimum-error azimuthal projections, such as Sir Henry James projection, but they have not received global recognition.

In 1951, Bomford projection, which belonged to the class of modified equal-area azimuthal projections and is an oblique aspect of Aitoff-Hammer lenticular projection, was designed for a new edition of the Oxford World Atlas by a British surveyor and cartographer Guy Bomford (1899-1996). The peculiarity of this projection is that when turning a grid by $45^{\circ}$ counterclockwise, all parts of the land were visually imaged on the map.

In 1953, Miller Oblated Stereographic projection, which belonged to the class of modified conformal azimuthal projections, was proposed by a American surveyor and cartographer Osborn Maitland Miller (1897-1979). In cartographical literature to define a projection sometimes other synonymic forms are used, including Miller Prolated Stereographic, Oblated Stereographic and Prolated Stereographic. The projection was used for mapping areas that are placed in an oval part of map, including Osborn Maitland Miller applied it when creating a maps of Africa and Europe (1953) and the Eastern Hemisphere (1955, in combination with several non-conformal projections) and Lorenzo Porter Lee-when creating a map of the Pacific ocean (1974). When creating a map of Europe and Africa is used a variant with symmetry concerning the central meridian and in all other cases - carthographical grid has not the axes of symmetry.

A separate group of modified azimuthal projections in transverse aspect includes lenticular azimuthal projections. In 1889, a Russian scientist and cartographer David Alexandrovich Aitoff (1854-1933) announced a very simple modification of the equatorial aspect of an equidistant azimuthal projection - Aitoff projection. Doubling longitudinal values enabled the whole world to fit in the inner disc of the map; the horizontal scale was then doubled, creating a 2:1 ellipse. As a result, the map is neither azimuthal nor equidistant, except along the Equator and central meridian. Neither is it equivalent or conformal. The Aitoff projection is a very interesting compromise between shape and scale distortion. It clearly shows the Earth's shape with less polar shearing than Mollweide's elliptical projection. However, this influential design was quickly superseded by Hammer's work.

In 1892, properly crediting David Alexandrovich Aitoff's previous work, German surveyor and cartographer Herman Heinrich Ernst von Hammer (1858-1925) applied exactly the same principle to Lambert's azimuthal equal-area projection. The resulting 2:1 elliptical equal-area design, called by the author AitoffHammer projection, by others at first Hammer-Aitoff projection and then simply the -Hammer projection, soon became popular and is used even today for world maps. It was itself the basis for several modified projections, like the oblique contribution by William A. Briesemeister. It is widely used in astronomy, in creating the star maps, in microbiology, in philately and in other spheres of human activity. The strong superficial resemblance of Aitoffs and Hammer's projections led to considerable confusion, even in technical literature.

In 1921, a German cartographer Oswald Winkel (1874-1953) proposed the third and best known hybrid projections called Winkel Tripel projection (from the German for triple, possibly referring to a triple compromise of reduced shape, area and distance distortion). Like his two other proposals, it is defined by a simple arithmetic mean including the equidistant 

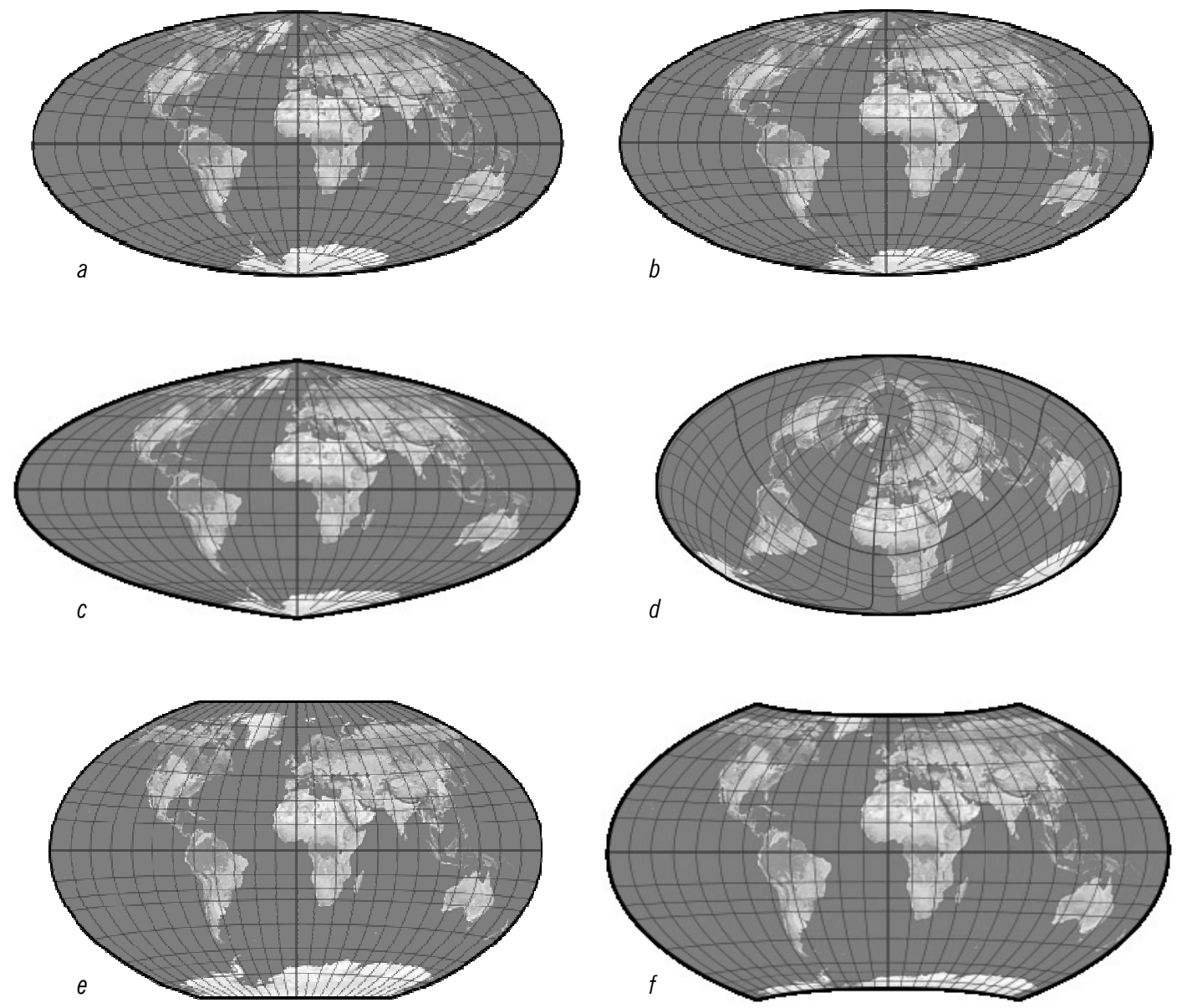

Fig. 9. Modified lenticular azimuthal projections: a) Aitoff; b) Hammer; c) Eckert-Greifendorff; d) Briesemeister; e) Winkel III; f) Wagner VII. Source: D. Strebe, "Geocart 3. User's Manual"

cylindrical projection and Aitoff projection, using an arbitrary value for standard parallels. Winkel's Tripel projection is peculiarly irregular: it is neither equal-area nor conformal; parallels are straight at the Equator and poles, curved elsewhere; the scales are constant, but not equal, only at the Equator and central meridian. Nevertheless, it manages to present a pleasant and balanced view of the world, which led to its choice by several popular atlases. In 1998 , it was selected by the prestigious National Geographic Society for its new reference world map, in place of the Robinson projection.

The Eckert-Greifendorff projection announced in 1935 by a German cartographer

\section{Friedrich Eduard Max Eckert-Greifendorff} (1868-1938) stretched the corresponding portion of a Hammer projection. In other words, it was exactly the same idea as Hammer's, but with longitude compressed four times and the horizontal scale multiplied fourfold. Before rescaling it uses only a narrow region near the central meridian of the original azimuthal map; as a consequence, parallels are almost straight lines.

In 1941 and 1949, a German cartographer Karlheinz (Karl Heinrich) Wagner (18921962) proposed his own seventh and ninth equal-area azimuthal map projections - Wagner VII (Hammer-Wagner) and Wagner IX 
(Aitoff-Wagner), which was a modification of the Aitoff and Hammer projections with changed scales. The projections are used to create world maps and climatic maps of Commercial Department of the U.S. Government.

In 1953, an American cartographer and geographer William A. Briesemeister (18841967) published quite a simple and very similar projection to Hammer's. The oblique equal-area modified the azimuthal projection with a central point $45^{\circ} \mathrm{N}$ and $10^{\circ} \mathrm{E}$ is called the Briesemeister projection, and its ratio of axes is 7:4. It is used to create a world map with grouping of continents in the center of projection.

\section{Multi-scale projections}

The creation of new azimuthal projections in the $20^{\text {th }}-21^{\text {st }}$ centuries became quite challenging, since their equations include a small number of variables that explain the limited variability of this class of projections compared with cylindrical and especially pseudocylindrycal projections. Variations of variables in the vast majority of cases led to the creation of arbitrary or conventional azimuthal projections. One of them was proposed in 1957 by Swedish cartographer Stig Torsten Erik Hägerstrand (1916-2004). Using the method of "magnifying glass" for multi-scale images, Hägerstrand created a projection in which the distance from the center decreases in proportion to the logarithm of the actual distance. However, this approach cannot be used for large-scale mapping, so the projection is only used for creating medium- and small-scale maps.

For the purpose of focusing attention on a particular area and surrounding areas in 1987, American cartographer John Parr Snyder developed a series of azimuthal projections with the effect of magnifying glass - "MagnifyingGlass" projections. In two of these cases, the mapping area in the middle of the circle used Postel equidistant projection or Lambert equal-area projection, and in the other four cases stereographic, gnomonic or other azimuthal projections were used. Snyder was a world authority in the field of mathematical cartography, and he developer of a number of new map projections, including projections of satellite navigation, oblique and equal-area "Magnifying-Glass" azimuthal projections. He developed his own computer program to create cartographical grids for more than 120 projections.

\section{Retroazimuthal projections}

They are a special group of azimuthal map projections. In western literature the retroazimuthal projection was first proposed in 1909 by a British economist, mathematician and cartographer James Ireland Craig (1868-1952). In 1910, an alternate version was proposed almost immediately thereafter by a German cartographer Herman Heinrich Ernst von Hammer. The main property of these projections consists in that the directions (azimuths) from every point of the map to chosen central point are correct. In this respect the maps differ from the usual azimuthal projections that render azimuths from the center correctly. As is the case with the normal azimuthal projections, the retroazimuthal condition is not sufficient to completely specify the projection, since two properties are required for most map projection. In Craig's (1910) version, the meridians are equally spaced, straight parallel lines perpendicular to a horizontal line through the origin. Hammer introduced the sensible alternate condition that all places should be at their proper distance from the center, a condition comparable to that defining the azimuthal equidistant projection. This condition changes both the spacing and the shape of the meridians and parallels, because the meridians become curved lines and the curvature of the parallels is modified. Probably in the case of normal azimuthal projections the property of equidistance can be substituted by the term of radial distance, but there is no obvious reason for doing it.

Jackson (1968) modified the spacing of the straight parallel meridians to obtain slight variants. When the meridians were spaced according to the sine of the longitude difference, he showed that the parallels of latitude are ellipti$\mathrm{cal}$, and when they were spaced as the tangent of one half of the longitudinal difference then the parallels were parabolas. If the spacing is equal 
to the tangent of the difference then the parallels become hyperbolas. He also provided a variant with curved meridians, and a "retroazimuthal stereographic" (but not conformal) projection. ing to Snyder, Gilbert of Bell Telephone Laboratories satirically constructed a retroazimuthal projection centered on Wall Street in New York City, the Mecca of the financial world. Others
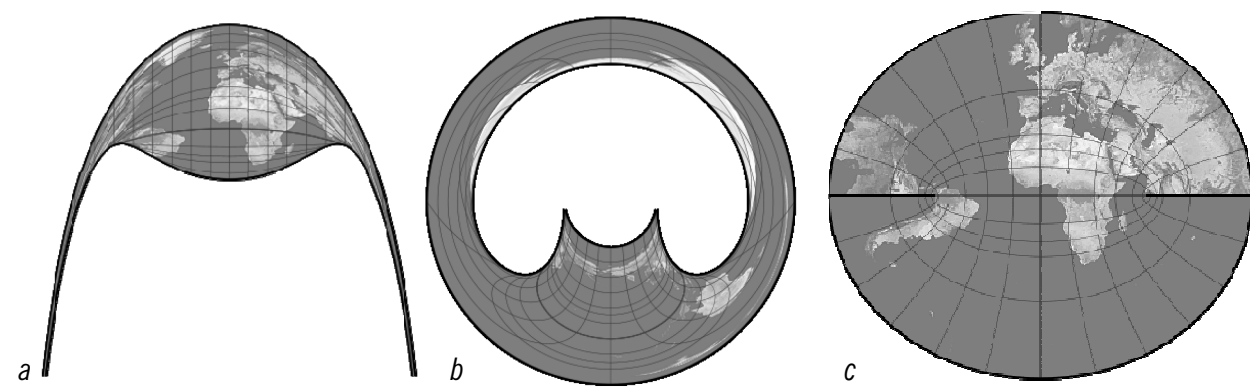

Fig. 10. Retroazimuthal projections: a) Craig (Mecca projection); b) Hammer; c) Littrow. Source: D. Strebe, "Geocart 3. User's Manual"

The projection devised by an Austrian astronomer Joseph Johann Edler von Littrow (1781-1840) in 1833 is not only conformal but it also has the property that all places located on the central meridian have the property of being retroazimuthal (Maurer, 1919). It is also possible to have a projection that is retroazimuthal with respect to two spherical locations (Maurer, 1914, 1919). None of these projections can show the entire world without overlap. Craig's map, when expanded to the entire sphere, seems to look like a two dimensional orthographic view of a three dimensional hyperbolic paraboloid. The overlapping can be loosely envisioned as if coming from a projection of this onto the drawing plane. Of course the projection is not made in this way but rather is derived mathematically.

The initial incentive for these projections was to enable Muslims to determine the qibla, that is, the directions to the Ka'aba in Mecca. Craig (1910) also suggested that navy ships could use such a map centered on their home port to determine the direction of a radio station. A comparable use was later made by Hinks (1929) with a map centered at Rugby in the United Kingdom for colonials in the British Empire. Additionally, de Henseler (1971) produced an equidistant retroazimuthal map for the geophysical observatory in Addis Ababa. Accord- who studied the problem of determining the azimuth of the qibla include Schoy (1917) and Berggren (1980).

Instead of using a retroazimuthal projection, it is possible to indicate the magnitude of the retroazimuthal directions (retro-azimuths) on any map by means of isolines. The preferred projection for this is a conformal one. A map like this, for Rugby on the Mercator projection, was reported by Reeves (1929), and one for Mecca, also on the Mercator projection, has been prepared by Kimerling (2001). The conformal property of the Mercator projection makes the direct reading of azimuth angles quite easy. De Hesenler drew isolines on Miller's cylindrical projection and Hagiwara (1984) portrayed lines of equal retroazimuths on an azimuthal equidistant projection of the world centered on Mecca.

\section{Composite projections}

On the Earth's northern hemisphere, continental areas are clustered around the pole, while south of the Equator wide patches of ocean separate sparse mainlands; moreover, Africa and the Americas narrow down towards the South. This peculiar distribution of lands is the foundation for a group of interrupted star-shaped map projections centered on the North Pole with a more or less circular core (often a hemisphere) surrounded by lobes with the less impor- 
tant Antarctica split between their ends. Some star maps invert this pattern, with a southern polar aspect privileging oceans. Non-polar aspects are possible but virtually unknown, at least with manual computation.

As a rule, star projections are composite designs; polar azimuthal projections are natural

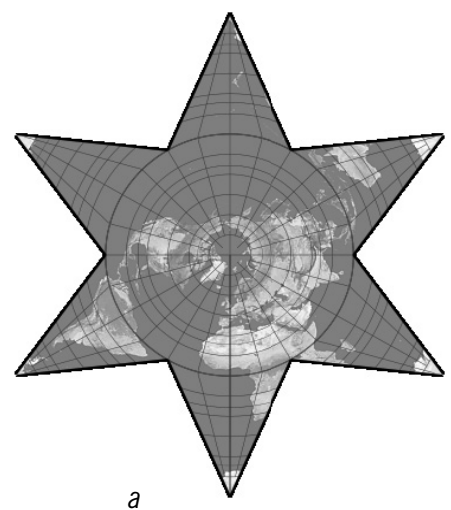

The Octants map was widely used in medieval cartography to create the appearance of oval projections. They, like star projections, divided the Earth's surface into eight equal parts, which are usually limited to four lines equator and meridians. Every spherical triangle is separately projected onto an octant of approximately triangular shape,

Fig. 11. Composite projections: a) Maurer (Regular star); b) Berghaus star.

Source: D. Strebe , "Geocart 3. User's Manual”

candidates for the core due to their circular parallels. The projection's creator must decide whether the lobes are uniform in size and shape, and how well they preserve the core's features like shape and spacing of parallels.

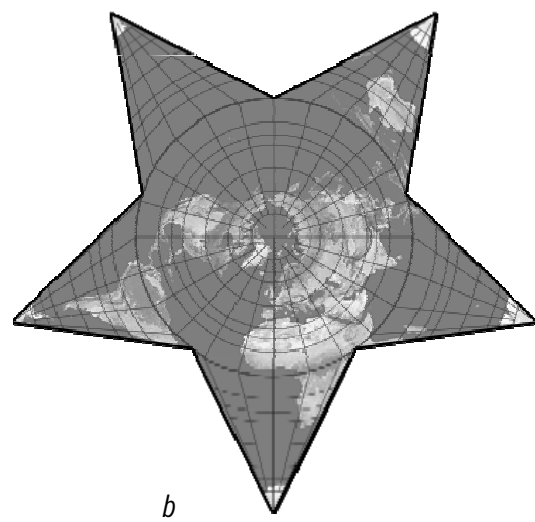

faces of which are the arcs of the circles with the center on the opposite vertices of an equilateral triangle. This type of octant is called Reuleaux triangle. Eight Reuleaux triangles form azimuthal projection called Octant Leonardo da Vinci.

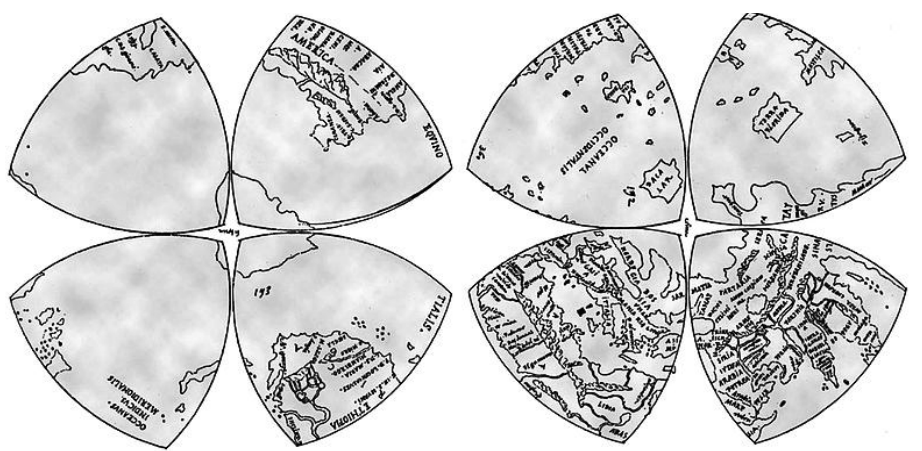

Fig. 12. World map - Mappa mundi in „Octant Leonardo da Vinci” projection.

Source: http://odtmaps.com/behind the_maps/amundi-map-details.asp, access: 5 November 2015

Star projections should not be mistaken for projections used for representing the celestial sphere; such star maps are at least as old as geographic charts.
Circa 1514 an Italian physicist, mathematician and naturalist Leonardo di ser Piero da Vinci (1452-1519) offered a projection which consists of separate segments. It did not have 
a cartographical grid and did not describe the method of design. In 1551, a French mathematician and cartographer Oronce Finé (14941555) published a cartographical grid of projection, but again without its detail. Based on the Octant Leonardo da Vinci's six detailed maps of Maremma, Toscana and Umbria were created. In this projection one of the first maps was created which marked a new world - the America and Southern Polar continent. Some critics believe that the map is not Leonardo's own work, because the accuracy and skill of its execution do not meet the high quality standards of the master. The projection was used in the creation of world maps of a French privateer, explorer and navigator Guillaume Le Testu (1556) and German reformed theologian Daniel Angelocrator (1616).

Although preceded by works by Leonardo da Vinci (an octant map, 1514) and Guillaume Le Testu (1556) which could be laid out as a circular arrangement of lobes, the first modern star projection was published in 1865 by Gustav Jäger. In its polar aspect, the inner hemisphere is an irregular octagon whose vertices are connected to the pole by straight semimeridians with an identical scale; all graticule lines are straight lines with linear scale, parallels broken at the boundary meridians, and meridians at the Equator. Each lobe in the outer hemisphere is a triangle exactly mirroring one of the core sectors.

A more influential design was almost immediately proposed after 1865 by August H. Petermann (1822-1878), a German cartographer and enthusiast of exploration (especially of polar areas), but its inner hemisphere is identical to the polar azimuthal equidistant's. On each lobe, parallels remain circular arcs centered on the pole, spaced the same as in the core but with variable scale; all semimeridians are straight lines. Sources differ on whether the eight lobes are uniform in size. Neither Jäger's nor Petermann's projections are either conformal or equal-area, but the latter is of course azimuthal in the inner hemisphere.

A variation of Petermann's map, Hermann Berghaus's (1797-1884) star projection (1879) reduced the number of appendages to five uniform lobes, with boundary meridians at $160^{\circ} \mathrm{W}, 88^{\circ} \mathrm{W}, 16^{\circ} \mathrm{W}, 56^{\circ} \mathrm{E}$ and $128^{\circ} \mathrm{E}$. Of all major land masses, Australia and Antarctica are interrupted. This design became much more popular than Petermann's, appearing in atlases and in the logo of the Association of American Geographers.

Like the original, only the core is azimuthal, and the whole map preserves neither area nor shapes. Further variations with any number of lobes greater than two can easily be done and, although not polyhedral projections by design, assembled into pyramids; with three symmetrical lobes, the map is an equilateral triangle foldable as a regular tetrahedron.

In 1935, Hans Theodor Julius Christian Karl Maurer presented a comprehensive catalogue of map projections, organized by hierarchical criteria. His taxonomy included empty categories, i.e., combinations of features not met by actual, existing projections; for illustration, he filled some of those gaps with designs of his own, including the star-shaped S231 and S233. The projection Maurer named S233 is a regular version of Jäger's map, with six identical lobes. In the polar aspect, all parallels and meridians are straight lines, parallels broken at boundary meridians and uniformly spaced along them; all meridians are broken at and uniformly spaced along the Equator. Each triangular lobe has an exact counterpart mirrored in the inner hemisphere. For the much more interesting proposal S231, Lambert's azimuthal equal-area projection was chosen for the inner hemisphere. In each lobe, only the central meridian is straight, and parallels are circular arcs centered on the North Pole. The scale along the central meridians is the same in both hemispheres, but mirrored at the Equator; the scale is constant along each parallel, and the same on a lobe's and on its counterpart in the core. Therefore the whole map is equal-area. Projections S231 and S233 were described with six uniform lobes, but can be extended to any number greater than one (S231) or two (S233).

A more recent star projection based on Lambert's equal-area azimuthal was devised by William William-Olsson (1968); however its core 
is bounded by the $20^{\circ} \mathrm{N}$ parallel instead of the Equator. The entire map is equal-area, but unlike Maurer's S231, the four lobes are derived from the Bonne/Werner pseudoconic projection: every parallel is a circular arc centered on the North Pole with a constant scale, and each central meridian is a straight line, with the same scale as on the core at $20^{\circ} \mathrm{N}$. Unfortunately, parallel lengths do not coincide at the boundary latitude on the pristine Lambert and Bonne/Werner projections. Matching the lengths at the junction requires increasing the scale of lobe parallels by the secant of half the boundary colatitude (the angular distance from the North Pole), for William-Olsson's choice, about $22.077 \%$. Areas are preserved by compressing the central meridians in lobes by the reciprocal amount.

Another hybrid azimuthal/pseudoconic star-shaped proposal is the "tetrahedral" projection introduced in 1942 by John Bartholomew (1923-2008), the fourth of a long lineage of map publishers with the same name and surname. He is also the author of the oblique Atlantis and the composite "Lotus", "Kite" and "Regional" maps. The "tetrahedral" map combines a northern polar azimuthal equidistant core limited by the $20^{\circ} 30^{\prime \prime} \mathrm{N}$ parallel (instead of the Equator adopted by Berghaus) with three identical lobes using the equal-area Werner projection maintaining the same parallel spacing. Again, parallel scales are not the same in the two base projections except at the poles, thus parallels must be lengthened in the lobes by about $26.6 \%$. Since, unlike in William-Olsson's design, parallel spacing is not reciprocally reduced, not even the lobes are equal-area.

Published in both northern and southern polar aspects, this projection apparently owes its name to a fortuitous resemblance of its lobe arrangement to a common lay-out for unfolded tetrahedra; it is unrelated to true polyhedral maps.

The analysis of the construction and directions of uses of the most famous azimuthal map projections allows to determine priority areas for further research in this branch and to define the set of subclasses within which it is possible to search new projections. These, first of all, should include modern perspective, composite and multi-scale modified azimuthal map projection. The general classification scheme azimuthal map projections do not limit the possibilities of the appearance of new subclasses of such class of projections.

\section{Bibliography}

d'Avezac de Castera-Macaya M.A.P., Coup d'oeil historique sur la projection des cartes de géographie, "Societe de Geographie, Bulletin. Series 5”, 5, 1863, (Apr-May), pp. 257-361; (June), pp. 438-485.

Balchin W.G.V., Map Projections in History, "Impulse", 2, 1957, pp. 9-13.

Barbie du Bocage J.D., Lacroix S.F., Notice historique et analytique sur la construction des cartes geographiques, "Journal des Sciences Militaires", 1, 1825, pp. 62-85.

Botley F.V., British and American World Map Projections from 1850-1950, Univ. of London, Master's Thesis in Geography, 1952.
Dahlberg R.E., Evolution of Interrupted Map Projections, "International Yearbook of Cartography”, 2, 1962, pp. 36-54.

Finsterwalder R., Die Projektion der Weltkarte in den Atlanten von Battista Agnese. Ein Beitrag zur Entwicklung der Kartennetze in der ersten Hälfte des 16. Jahrhunderts, "Acta Albertina Ratisbonensia”, 46, 1989, pp. 19-27.

Flegg G., Map Projections, in Projection in History of Mathematics, unit 5: Projection, Milton Keynes, Open University Press, 1975, pp. 22-25.

Grüll J., Heinrich Christian Albers (1773-1833). Leben und Wirken des Lüneburger Kartographen, 
"Kartographische Nachrichten”, 23 (5), 1973, pp. 196-203.

Hall E.F., Gerard Mercator. His Life and Works, "Journal of American Geographical Society of New York", 10 (4), 1878, pp. 163-196.

Harley J.B., Woodward D., The History of Cartography, vol. 1-2, Chicago 1987-1994.

Herrmann A., Marinus von Tyrus, "Petermanns Mitteilungen. Erganzungsheft", 209, 1930, pp. 45-54.

Hinks A.R., Edward Wright and Mercator's Projection, in: $12^{\text {th }}$ International Geographical Congress, Cambridge, July 1928. Report of the Proceedings, Nendeln 1972, p. 109.

Kennedy M., Kopp S., Understanding Map Projections, Redlands 1994-2000.

Keuning J., The History of Geographical Map Projections until 1600, "Imago Mundi", 12, 1955, pp. 1-24.

Mollweide C.B., Mappirungskunst des Claudius Ptolemaeus, ein Beitrag zur Geschichte der Landkarten, "Zach's Monatliche Korrespondenz zur Beförderung der Erd- und Himmels-Kunde”, 11 (1805), pp. 319-340 (Apr.), 504-514 (June); 12 (1805), pp. 13-22 (July).

Robinson A.H. et al., Elements of Cartography, New York 1995.
Schröder E., Kartenentwürfe der Erde. Kartographische Abbildungsverfahren aus mathematischer und historischer Sicht, Frankfurt am Main 1988.

Snyder J.P., Flattening the Earth. Two Thousand Years of Map Projections, Chicago 1993.

Snyder J.P., Map Projections. A Working Manual, Washington 1987 (http://pubs.er.usgs.gov/ publication/pp1395, access: 15 September 2015).

Strebe D., Geocart 3. User's Manual. Manual Describes Geocart 3.1, Seattle 2009.

Thrower N.J.W., Projections of Maps of Fifteenth and Sixteenth Century European Discoveries, Madrid 1993, pp. 81-87.

Tobler W.R., Medieval Distortions. The Projections of Ancient Maps, "Annals of the Association of American Geographers", 56 (2), 1966, pp. 351-361.

Бугаевский М.М., Математическал картография, Москва 1998.

Фролов Ю., От Клавдия Птолемея до Риго-

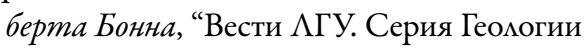
и Географии”, 6 (1), 1963, pp. 118-125. 


\section{Aspekty historyczne rozwoju teorii odwzorowań azymutalnych}

\section{Streszczenie}

Problem odwzorowania powierzchni Ziemi na płaszczyźnie zajmuje matematyków i kartografów od ponad 2000 lat. Zagadnienie to ma istotne znaczenie nie tylko dla teoretyków kartografii, ale również dla użytkowników map, ponieważ $\mathrm{w}$ rezultacie przekształceń wynikających z rodzaju odwzorowania następuje zniekształcenie pewnych zależności geometrycznych występujących na powierzchni Ziemi. W odróżnieniu od wielu publikacji przedstawiających odwzorowania kartograficzne jako jedno z zagadnień kartografii matematycznej w niniejszym artykule skupiono się na rozwo-

ju i zastosowaniu wyłącznie odwzorowań azymutalnych (płaszczyznowych), śledząc zmiany od czasów starożytnych do współczesnych. Omawiając podstawowe cechy poszczególnych odwzorowań azymutalnych, przedstawiono ich szczegółową klasyfikację, m.in. na typy związane z położeniem środka rzutu (np. centralny, stereograficzny, ortograficzny), nie mające charakteru rzutów, jak najpopularniejsze z nich odwzorowanie Postela (równoodległościowe) czy Lamberta (równopolowe), a także na wszelkie modyfikacje typów podstawowych.

Keywords: types of azimuthal map projections, perspective and non-perspective azimuthal projections, modified azimuthal projections, retroazimuthal projections, composite projections

Slowa kluczowe: typy odwzorowań kartograficznych, odwzorowania azymutalne perspektywiczne i nieperspektywiczne, odwzorowania azymutalne modyfikowane, odwzorowania retroazymutalne, odwzorowania łączone

Pavel Korol - docent Wschodnioeuropejskiego Narodowego Uniwersytetu im. Łesi Ukrainki w Łucku, zatrudniony w Katedrze Geodezji, Gospodarki Gruntami i Katastru (e-mail: pavking@rambler.ru)

Rostislav Sossa - profesor Kijowskiego Uniwersytetu Narodowego im. Tarasa Szewczenki, dyrektor Państwowego Przedsiębiorstwa Naukowo-Produkcyjnego „Kartografia” w Kijowie (e-mail: admin@ukrmap.com.ua) 